\title{
A Study of Developing a System Dynamics Model for the Learning Effectiveness Evaluation
}

\author{
Tian-Syung Lan, ${ }^{1}$ Yu-Hua Lan, ${ }^{2}$ Kai-Ling Chen, ${ }^{3}$ Pin-Chang Chen, ${ }^{1}$ and Wen-Cheng Lin ${ }^{1}$ \\ ${ }^{1}$ Department of Information Management, Yu Da University of Science and Technology, Miaoli 36143, Taiwan \\ ${ }^{2}$ Center for General Education and Core Curriculum, Tamkang University, New Taipei City 25137, Taiwan \\ ${ }^{3}$ Department of Leisure Recreation and Travel Management, Toko University, Chiayi 61363, Taiwan
}

Correspondence should be addressed to Pin-Chang Chen; chenpc@ydu.edu.tw

Received 15 September 2013; Accepted 14 October 2013

Academic Editor: Teen-Hang Meen

Copyright (C) 2013 Tian-Syung Lan et al. This is an open access article distributed under the Creative Commons Attribution License, which permits unrestricted use, distribution, and reproduction in any medium, provided the original work is properly cited.

\begin{abstract}
This study used the research method of system dynamics and applied the Vensim software to develop a learning effectiveness evaluation model. This study developed four cause-and-effect chains affecting learning effectiveness, including teachers' teaching enthusiasm, family involvement, school's implementation of scientific activities, and creative teaching method, as well as the system dynamics model based on the four cause-and-effect chains. Based on the developed system dynamic model, this study performed simulation to investigate the relationship among family involvement, learning effectiveness, teaching achievement, creative teaching method, and students' learning interest. The results of this study verified that there are positive correlations between family involvement and students' learning effectiveness, as well as students' learning effectiveness and teachers' teaching achievements. The results also indicated that the use of creative teaching method is able to increase students' learning interest and learning achievement.
\end{abstract}

\section{Introduction}

When entering the third grade in elementary school, students are facing the new challenge in the learning of "science and technology" subject. Because the learning motivation and learning method of science and technology are significantly different from those of other fields, it is necessary to investigate the learning effectiveness of the "science and technology" subject [1]. Many variables may affect students' learning effectiveness of science and technology. The research architecture of this study included four parts that affect learning effectiveness, which are teachers' teaching enthusiasm, family involvement, school's implementation of scientific activities, and creative teaching method. Each of the above subsystems is mutually connected with one another to develop causeand-effect relationships [2,3].

Most of the past studies on the issues concerning the learning of science and technology of elementary schools are static studies, which cannot assess the postimplementation policies $[4,5]$. This study used Vensim software to develop the framework of a systemic model from the perspective of system dynamics and performed dynamic simulation for analysis and explanation. This study investigated the learning effectiveness of science and technology based on system dynamic model.

This study elevated the previous static studies to a dynamic level. The suggestions proposed based on the simulation results can serve as reference for educators and policymakers in the academic community. It is hoped that this study can help in improving the learning motivation and learning effectiveness of science and technology of students and apply the model-based concepts to different learning fields to further extend such concepts to other relevant studies.

\section{Research Method}

This study used the research methods of system dynamics and the specific package software Vensim software for system dynamics to develop the model and executed system dynamics equations to perform analyses and discussions.

System dynamics is a system analysis theory created by Forrester in 1968 [6]. System dynamics used the feedback characteristic of information in the system to develop 




FIgURE 1: Cause-and-effect chain diagram of teacher's teaching enthusiasm and students' learning effectiveness.

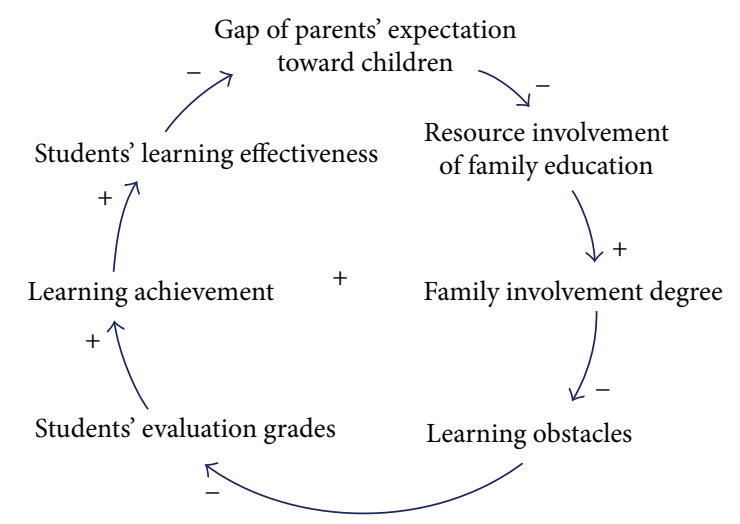

Figure 2: Cause-and-effect chain diagram of family involvement and learning effectiveness.

model equations, simulate, and predict the implementation of various policies to achieve the objective of improvement [7]. System dynamics excels in the processing of high-level, nonlinear, and time-varying issues, and it can still be used for investigation under the condition of absence of data [8].

Vensim software is the software developed by Ventana Inc. for model development of system dynamics. It uses various graphics as interface to constitute a complete system dynamics model [9]. The cause-and-effect relationships among various factors can be explained. Its major function is to perform simulation, analysis, and prediction based on the model [10].

\section{Cause-and-Effect Chain}

This study developed four cause-and-effect chains affecting learning effectiveness, including teachers' teaching enthusiasm, family involvement, school's implementation of scientific activities and creative teaching method.

During the teaching process, the better the teacherstudent interaction is, the better the behavioral performance of students is. As long as teachers give proper expectation to students according to their abilities, their high learning motivation can be triggered, their learning effectiveness will

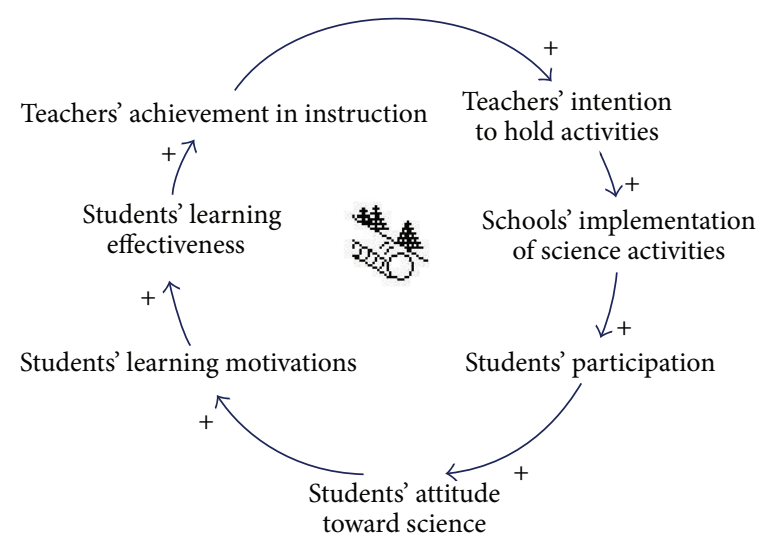

FIGURE 3: Cause-and-effect chain diagram of school's implementation of scientific activities and learning effectiveness.

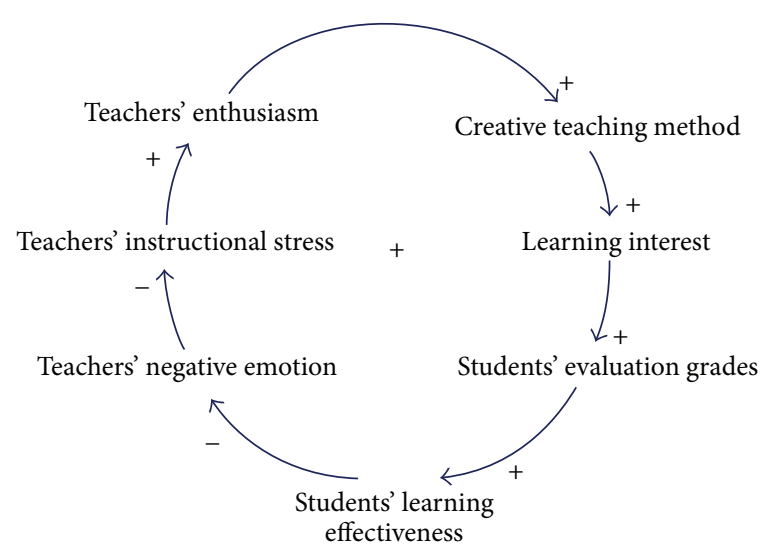

FIGURE 4: Cause-and-effect chain diagram of creative teaching method and learning effectiveness.

become better, and teachers-students relationship will be improved to inspire teachers' teaching enthusiasm. Based on the above, the cause-and-effect chain diagram of relevant factors affecting teachers' teaching enthusiasm and students' learning effectiveness is drawn, as shown in Figure 1.

If parents are willing to spend more time accompanying children to learn, the learning obstacles of science and technology encountered by children will be reduced. Once learning obstacles are reduced, students' learning motivation will be enhanced to further affect their academic performance, learning achievement, and learning effectiveness. This study develops the cause-and-effect chain diagram of relevant factors affecting family involvement and learning effectiveness, as shown in Figure 2.

The scientific activities implemented by schools are mainly instructed by science and technology subject teachers. The success of such activities and the performance of students are subject to the intention and involvement of instructors. The higher the teacher's intention to hold activities is, the better the students' performance is. In this way, students' learning motivation can be triggered and enhanced, and their learning effectiveness can also be improved. This study develops the cause-and-effect chain diagram of relevant factors 


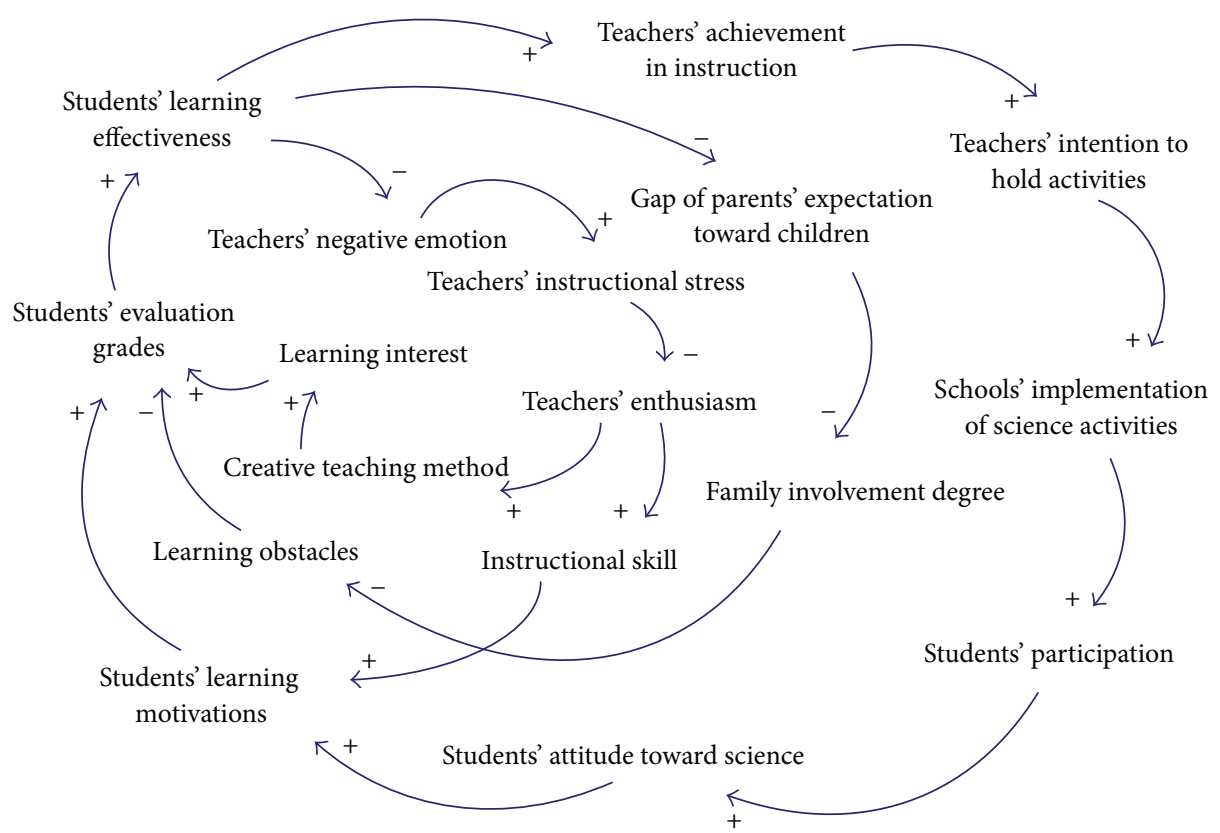

Figure 5: Cause-and-effect chain diagram of learning science and technology.
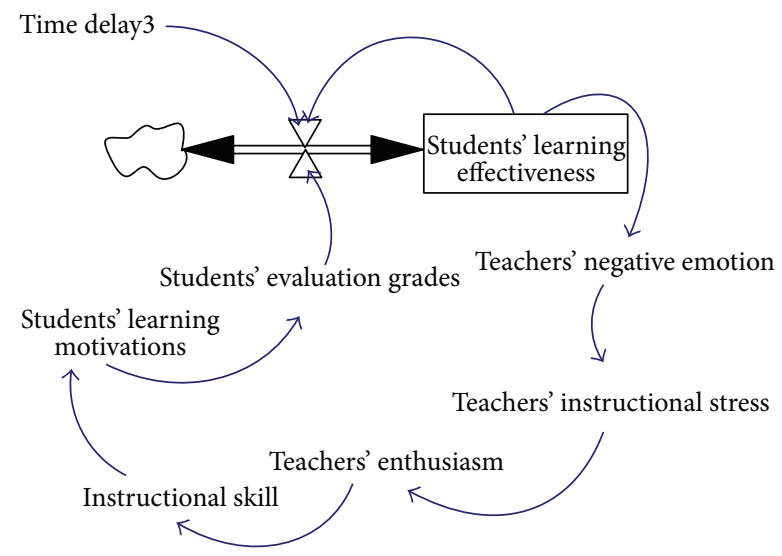

FIGURE 6: System dynamics model of teachers' teaching enthusiasm and students' learning effectiveness.

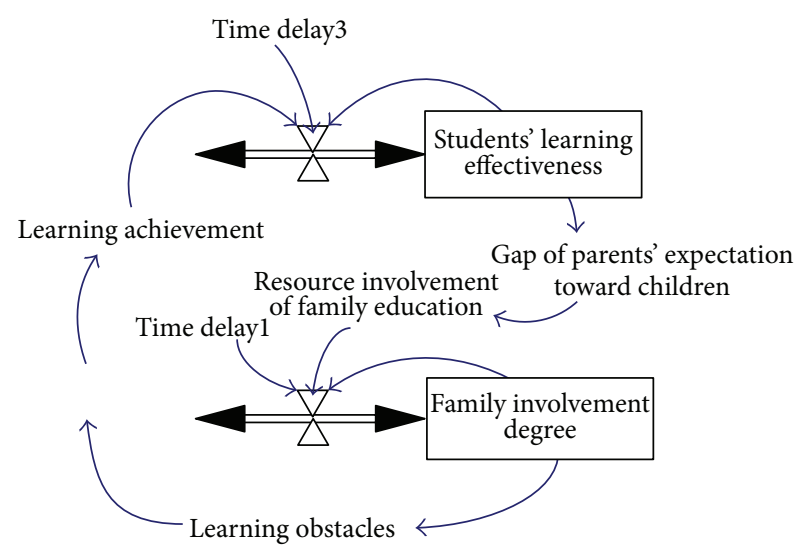

Figure 7: System dynamics model of family involvement and learning effectiveness. affecting schools' implementation of scientific activities and learning effectiveness, as shown in Figure 3.

Teaching methods have constantly changed and evolved with the progress of time. With the technology of teaching aids and materials, creative teaching method has been constantly created. New teaching method will increase students' learning interest, trigger their learning motivation, develop their scientific attitude, and improve their learning achievements and learning effectiveness. This study develops the cause-and-effect chain diagram of factors affecting creative teaching method and learning effectiveness, as shown in Figure 4 .

Based on the four cause-and-effect chain diagrams above, this study develops the cause-and-effect chain diagram of relevant factors affecting the learning effectiveness of science and technology, as shown in Figure 5.

\section{System Dynamics Model}

This study developed the system dynamics model based on the cause-and-effect chain diagrams, which are discussed as follows.

In the learning field of science and technology, teachers need sufficient teaching enthusiasm to encourage themselves to change teaching method and strategies and further trigger students' learning motivation and improve their learning intention. This study develops the system dynamics model of the relationship between teaching enthusiasm and learning effectiveness, as shown in Figure 6.

Parents' educational attitude toward the learning of various subjects will affect students' learning condition. During family involvement in children's education, other factors will intervene with the learning of science and technology. The major one is the assignment time of other subjects. This 


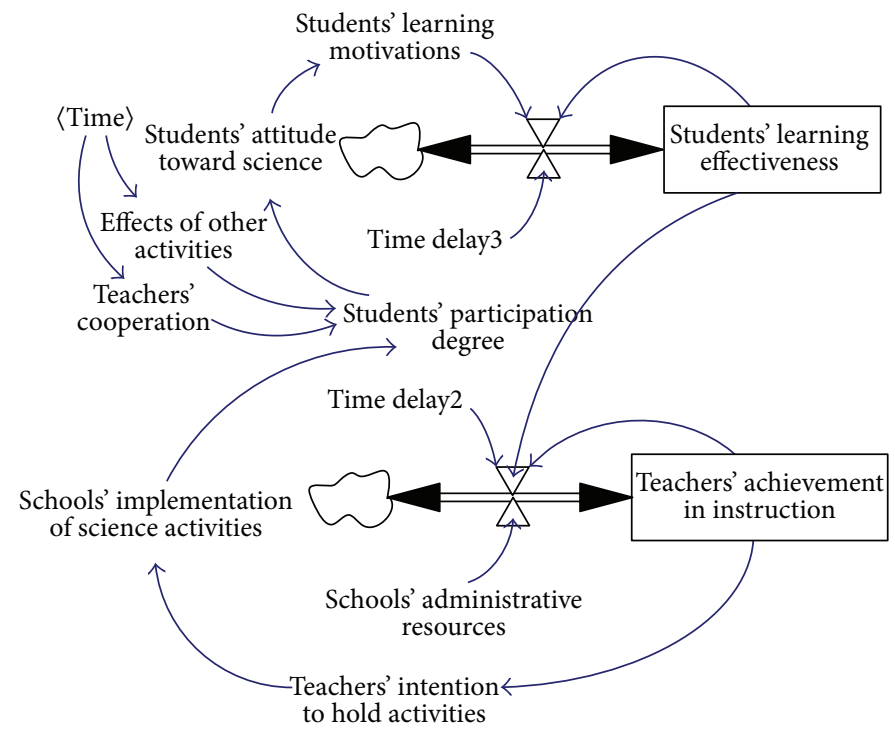

FIGURE 8: System dynamics model of school's implementation of scientific activities and learning effectiveness.

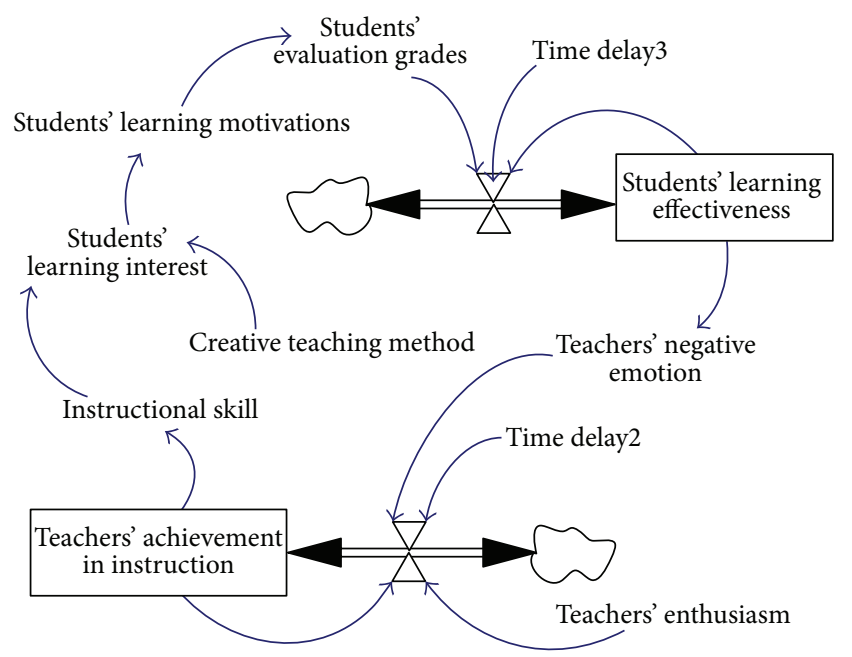

FIGURE 9: System dynamic model of creative teaching and learning effectiveness.

study develops the system dynamics model of the relationship between family involvement and learning effectiveness, as shown in Figure 7.

School's implementation or participation in scientific activities has a significant effect on students' learning motivation and learning effectiveness. Therefore, teachers' intention to hold or cooperate with activities affects students' scientific attitude and learning effectiveness. This study develops the system dynamic model of the relationship between school's implementation of scientific activities and learning effectiveness, as shown in Figure 8.

Creative teaching method can arouse the interest of students and trigger their learning motivation. In addition, creative teaching method can also change students' scientific attitude. This study develops the system dynamics model of the relationship between creative teaching method and learning effectiveness, as shown in Figure 9.

Based on the four system dynamics models above, this study integrated the four sub-models to develop the system dynamics model of science and technology, as shown in Figure 10.

\section{Results and Discussion}

Based on the developed system dynamic model, this study performed simulation to investigate the relationship among family involvement, learning effectiveness, teaching achievement, creative teaching method, and students' learning interest.

(1) Family involvement and students' learning effectiveness: the simulation of this system mainly investigated the relationship between family involvement and learning effectiveness. According to the simulation results, in the short term, there is a steady increase, as well as ups and downs, in family involvement, and so is learning effectiveness. In the long term, there is a highly positive correlation between them. In other words, the higher the family involvement is, the higher the students' learning effectiveness is, as shown in Figure 11.

(2) Students' learning effectiveness and teachers' teaching achievements: the simulation of this system mainly investigates the relationship between students' learning effectiveness and teachers' teaching achievements. The results showed that there is a positive correlation between students' learning effectiveness and teachers' teaching achievements. The higher the teaching achievement is, the higher the students' learning effectiveness is, as shown in Figure 12. 


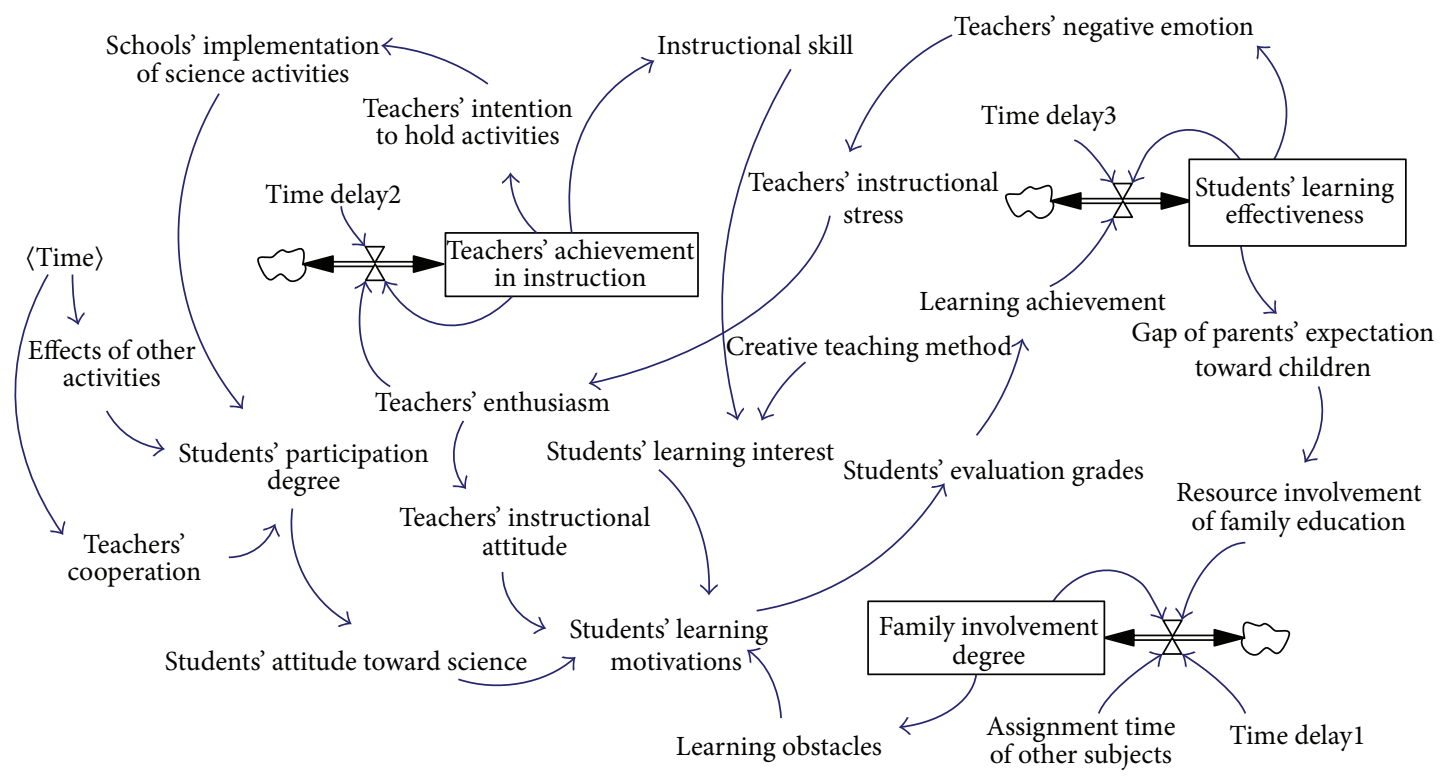

Figure 10: System dynamics model of learning science and technology.

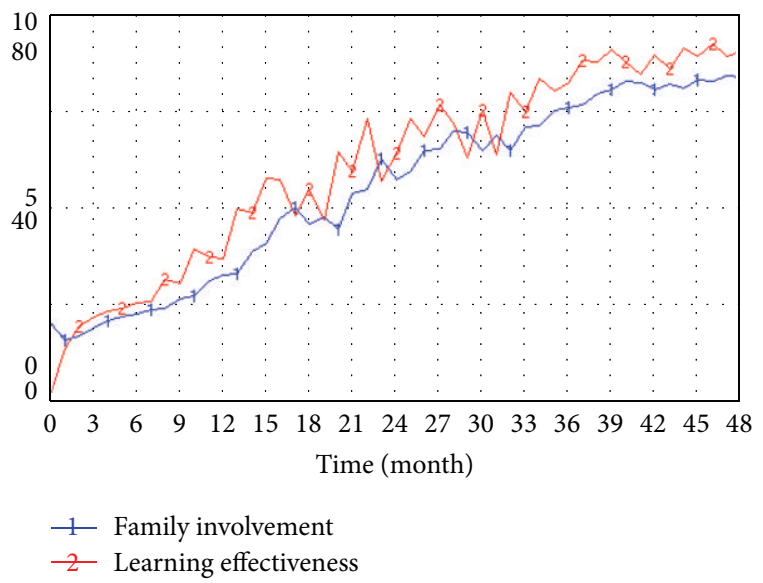

FIGURE 11: Analysis of family involvement and learning effectiveness.

(3) Effect of creative teaching method on students' learning interest: the simulation of this system mainly investigates the relationship between creative teaching method and students' learning interest. The use of creative teaching method can trigger students' learning interest. Apparently, in the beginning of learning science and technology, the use of different creative teaching methods can immediately arouse students' interest, as shown in Figure 13.

\section{Conclusion}

This study verified that there is a highly positive correlation between family involvement and students' learning effectiveness. In other words, family plays an important role in students' learning, and the role of parents is particularly

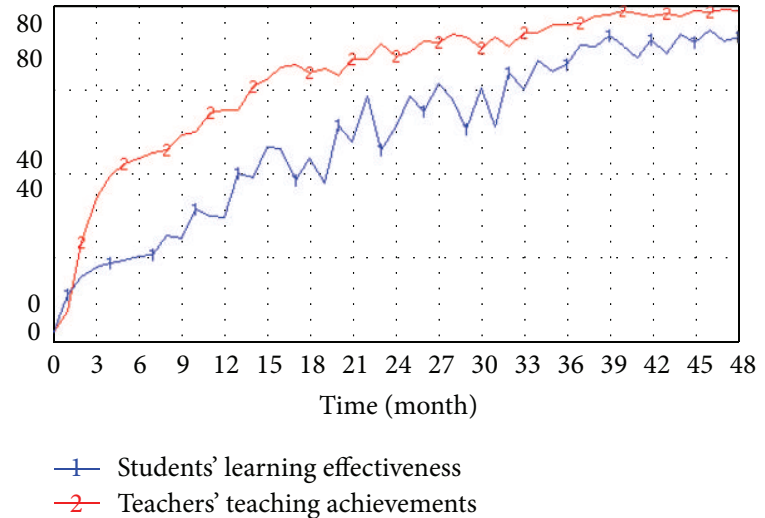

FIGURE 12: Analysis of students' learning effectiveness and teachers' teaching achievements.

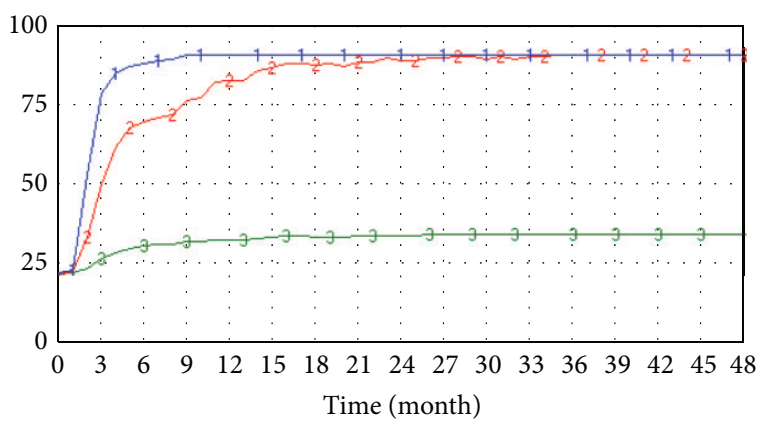

- Students' learning interest: creative teaching method
2 - Students' learning interest: current teaching method
-3 - Students' learning interest: traditional teaching method

FIGURE 13: Analysis of the effect of creative teaching method on students' learning interest. 
important. The learning of science and technology in elementary schools is different from the reading, speaking, listening, and writing of language, the comprehension and calculation of mathematics, or the memorization and induction of social science. Instead, it is the integration of learning approaches of various fields. Higher family involvement, lower obstacles encountered in the field of science and technology, and parents willing to help children complete their assignment in science and technology are beneficial to students, which can further improve their learning effectiveness.

This study also verified that there is a positive correlation between students' learning effectiveness and teachers' teaching achievements. Teachers can handle their teaching content and teaching method to obtain a sense of achievement from the gradual progress in learning effectiveness of students. Their sense of achievement is usually higher than students' learning effectiveness. Once teachers obtain a good sense of achievement, their teaching enthusiasm will be higher. They will maintain their teaching enthusiasm and aggressively engage in teaching. Under such an atmosphere, students' learning effectiveness will be better as well.

This study also indicated that the difference in teaching method has an effect on students' learning interest. The traditional narrative teaching has become outdated. However, there are still teachers using such a teaching method, which cannot arouse the learning interest of students at all. In the current learning environment filled with information and diversification, traditional teaching should have been eliminated and replaced by various newly arising teaching methods. The most popular teaching method at present is e-whiteboard, which has been used for three years. Teachers' use of e-whiteboard is attractive to students, which can significantly increase learning interest, as well as the enthusiasm for science and technology to further improve learning effectiveness. In the current learning environment filled with information and diversification, students' learning has changed, so teachers' teaching methods have to change as well. If teachers can use proper aids and other creative teaching methods during the use of e-whiteboard, students' learning interest will be increased and their learning achievements will be improved.

\section{References}

[1] S. S. Liaw, "Investigating students' perceived satisfaction, behavioral intention, and effectiveness of e-learning: a case study of the blackboard system," Computers and Education, vol. 51, no. 2, pp. 864-873, 2008.

[2] J. Gosen and J. Washbush, "A review of scholarship on assessing experiential learning effectiveness," Simulation and Gaming, vol. 35 , no. 2, pp. 270-293, 2004.

[3] G. L. Karns, "Learning style differences in the perceived effectiveness of learning activities," Journal of Marketing Education, vol. 28, no. 1, pp. 56-63, 2006.

[4] A. Lau and E. Tsui, "Knowledge management perspective on elearning effectiveness," Knowledge-Based Systems, vol. 22, no. 4, pp. 324-325, 2009.

[5] M. Wrzesien and M. A. Raya, "Learning in serious virtual worlds: evaluation of learning effectiveness and appeal to students in the e-junior project," Computers and Education, vol. 55, no. 1, pp. 178-187, 2010.

[6] J. W. Forrester, Principles of Systems, MIT Press, Cambridge, Mass, USA, 1968.

[7] J. D. Sterman, Business Dynamics: Systems Thinking and Modeling for a Complex World, Irwin McGraw-Hill, Boston, Mass, USA, 2000.

[8] M. Wu and H. Yan, "Simulation in software engineering with system dynamics: a case study," Journal of Software, vol. 4, no. 10, pp. 1127-1135, 2009.

[9] N. Helfrich and W. Schade, "Bringing distributed software development to SD modelling with vensim," in Proceedings of the 26th International Conference of the System Dynamics Society, Athens, Greece, July 2008.

[10] R. L. Eberlein and D. W. Peterson, "Understanding models with vensim," European Journal of Operational Research, vol. 59, no. 1, pp. 216-219, 1992. 


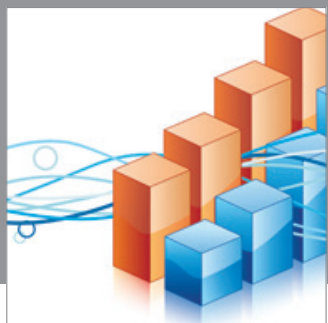

Advances in

Operations Research

mansans

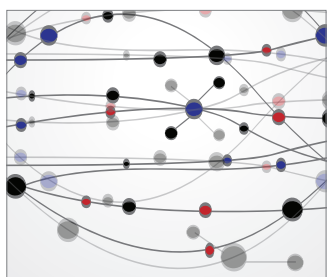

The Scientific World Journal
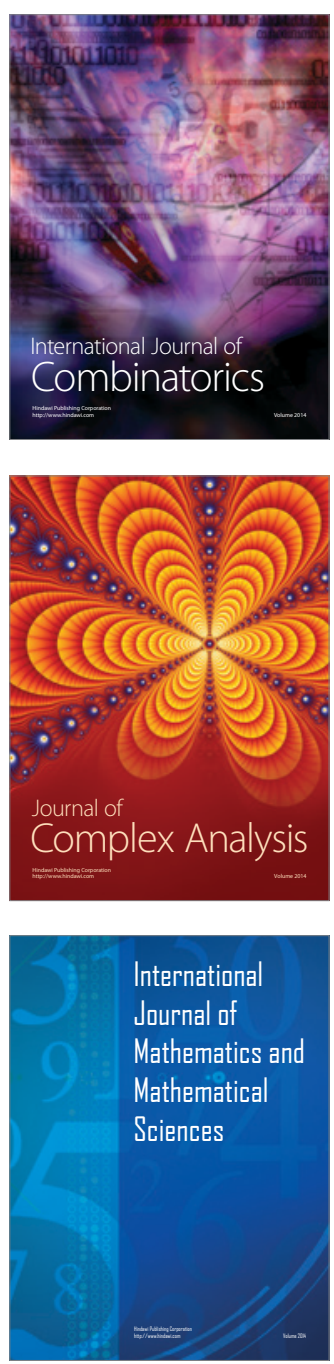
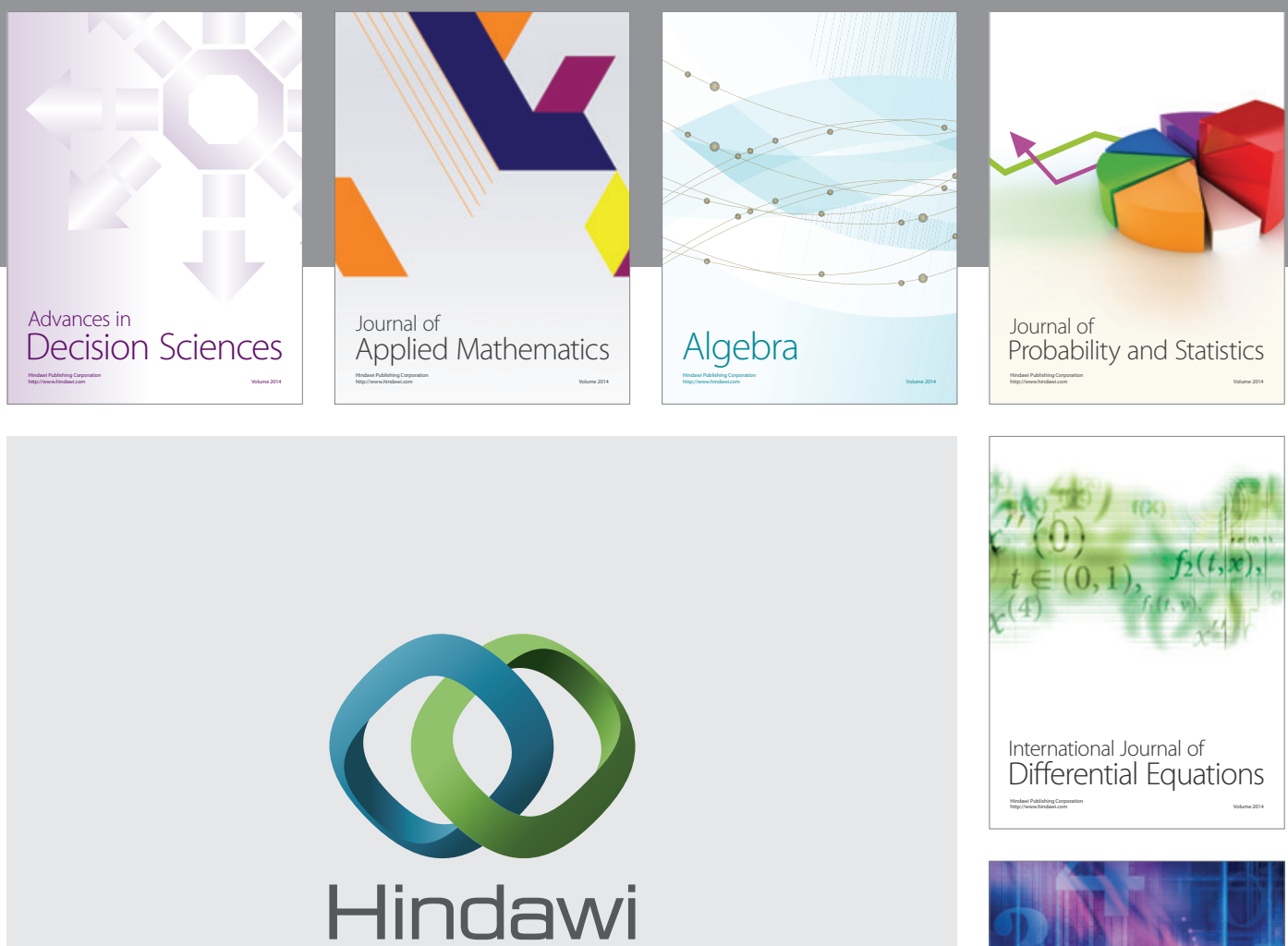

Submit your manuscripts at http://www.hindawi.com
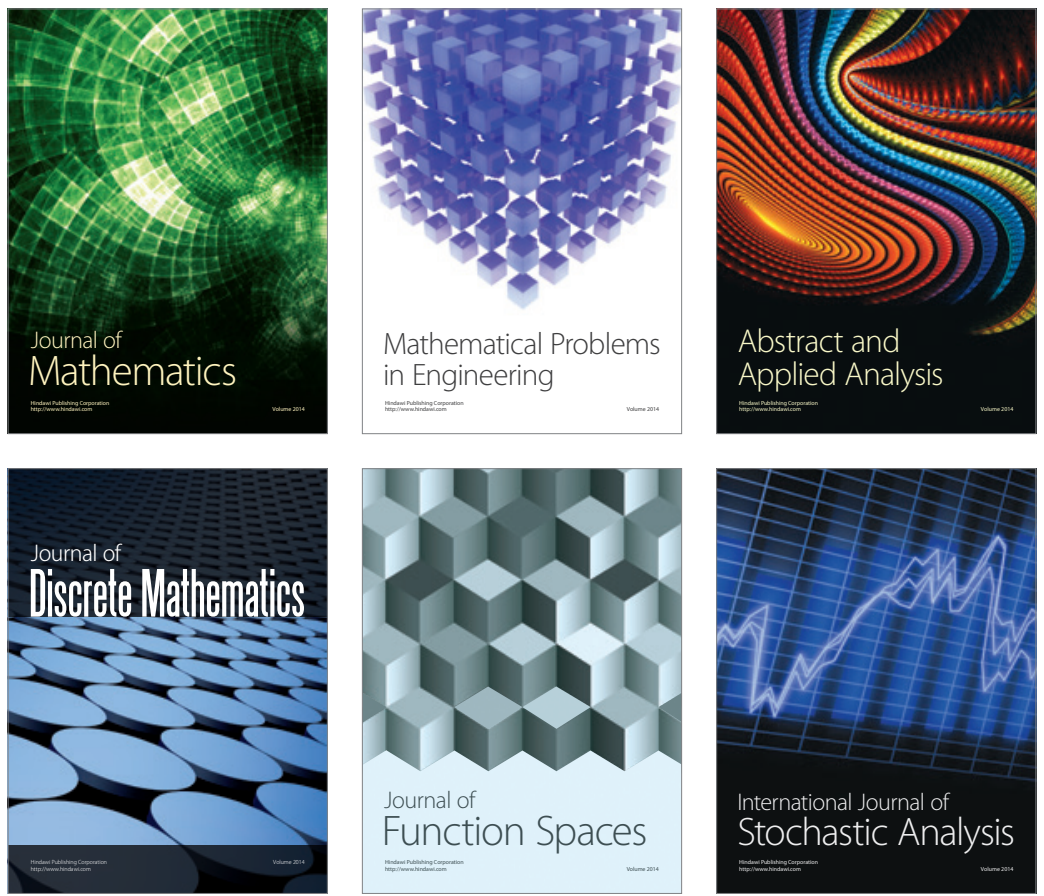

Journal of

Function Spaces

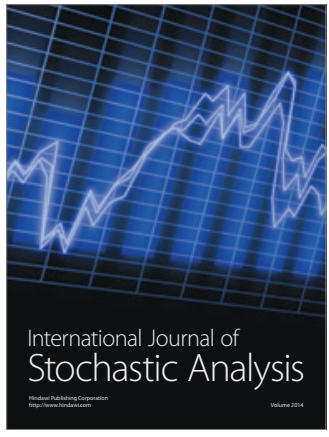

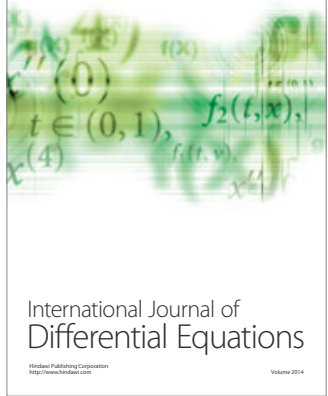
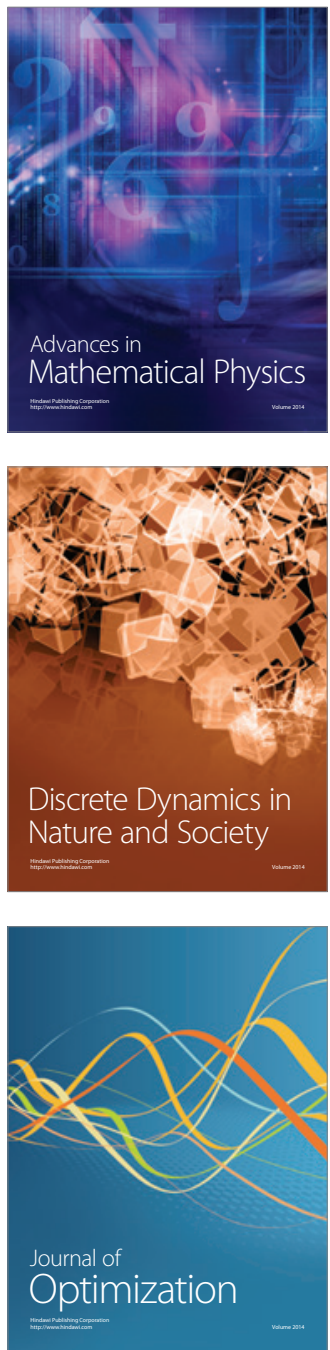